\title{
Cesium uptake by edible mushrooms and microorganisms isolated from mushroom substrata
}

\author{
C. Kuwahara, H. Sugiyama ${ }^{1}$ and F. Kato ${ }^{2}$ \\ Division of Environmental Health, Kanagawa Prefectural Public Mealth Laboratory, \\ Asahi-ku, Yokohama 241-0851, Japan \\ 1 Department of Radiological Health, National Institute of Public Health, \\ Minato-ku, Tokyo 108-8638, Japan \\ 2 Department of Microbiology, School of Pharmaceutical Sciences, Toho University, \\ Funabashi, Chiba 274-8510, Japan
}

\begin{abstract}
The concentrations of ${ }^{137} \mathrm{Cs}$ and stable $\mathrm{Cs}$ were measured in wild mushrooms, mushroom substrata and soils from Mt.Fuji in Japan. We then studed the Cs uptake by the edible mushroom, Pleurotus ostreans, through the cultured experiments using ${ }^{137} \mathrm{Cs}$ andior a stable $\mathrm{Cs}$ tracer. ${ }^{139} \mathrm{Cs}$ concentrations ill the fruiting bodies were $2-4$ orders of magnitude higher than those in the wild mushrooms collected in Japan. It was demonstrated that ${ }^{137} \mathrm{Cs}$ and

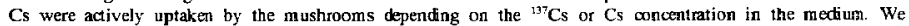
subsequently investigated the $C s$ sensitivity of microorganisms in the mushroom subsirata and $C$ s uptake by actinomyctes, one of the soil microorganisms in mushroom substrata. The number of bath bacteria and actinomycetes in the substrata decreased with increasing $\mathrm{Cs}$ concentration in the medium. Actinomycetes in the mushroom substrata were more sensitive to Cs than other bacteria. In the presence of $5 \mathrm{mM} \mathrm{CsCl,} \mathrm{Cs} \mathrm{uplake} \mathrm{by}$ several strains of actinomyces was generally high, and the growth was partially inhibited compared with the Cs resistant strains, Streptomyces lividans TK24 and Streptomyces sp. TOHO-2.
\end{abstract}

\section{INTRODUCTION}

The studies following the Chernobyl accident clarified that the concentration of radiocesium in mushrooms was higher than in other vegetables and types of vegetation, and that mushrooms have a tendency to accumulate radiocesium [1-3]. The number of reports on the concentration and transfer of radiocesium in wild and cultivated mushrooms has been increasing, however a clear explanation of the characteristies and mechanism of ${ }^{137} \mathrm{Cs}$ uptake by mushrooms has not been established. Yoshida et al. noted that the ${ }^{1{ }^{17} \mathrm{Cs}}$ concentration in mushrooms reflected the layers in which their mycelia were grown [2]. Additionally, several researchers indicated that microorganisms are involved in a high retention of ${ }^{13}$ Cs in the surface soil layer [4-6]. We supposed that the process of ${ }^{137} \mathrm{Cs}$ transfer to mushrooms is not only a direct transfer of soluble ${ }^{137} \mathrm{Cs}$ from the substrata, but also an indirect way from the soil microorganisms that accumulate ${ }^{137} \mathrm{Cs}$, as in a food chain. For example, Pleurotus ostreatus (oyster mushroom) and five species of Pleurotus were reported to prey on nematodes $[7,8]$, and soil nematodes prey on soil bacteria with accumulated ${ }^{137} \mathrm{Cs}$. We supposed that this type of food chain would contribute to a high ${ }^{137} \mathrm{Cs}$ accumulation in wild mushrooms. In this study, we first determined ${ }^{137} \mathrm{Cs}$ and $\mathrm{Cs}$ concentrations in mushrooms and mushroom substrata from a sub-alpine forest of $\mathrm{Mt}$. Fuji, and examined the concentration ratios (CRs) of cultured mushrooms, Pleunotus ostreatus Y-1 and wild mushrooms. We investigated Cs sensitivity of the microorganis ms and Cs uptake by strains of actinomycetes isolated from the mushroom substratum. By scanning electron microscopy (SEM)-energy dispersive $X$-ray microanalysis (EDX) and ${ }^{133} \mathrm{Cs}-\mathrm{NMR}$ spectrometry, the states of $\mathrm{Cs}$ in the mycelia were examined.

\section{MATERIALS AND METHODS}

\subsection{Samples and analyses of wild mushrooms}

Elcren species of mushroom, surface soil samples $(0-10 \mathrm{~cm})$ and two soil samples where mushrooms had not grown, were collected from the sub-alpine forest of Mt. Fuji (1600-2200m above sea level) in Yamanashi Prefecture, Japan, in October 1998. Mushroom samples and the substrata were freeze-dried and pulverized. Dried samples were placed in plastic bottles and concentrations of radionuclides were determined with a Ge-detector. Stable $\mathrm{Cs}$ was measured by instrumental neutron activation analysis (INAA) after cooling for several months as described by Kuwahara et al. [9]. 


\subsection{Measurement of ${ }^{137} \mathrm{Cs}$, stable $\mathrm{Cs}$ and $\mathrm{K}$ in cultured fruiting bodies of the edible mushroom Pleurotus ostreatus}

The culture medium was prepared by the method of Sugiyama et al.[10]. For ${ }^{137} \mathrm{Cs}$ uptake experiments, 10 $\mathrm{k} \mathrm{Bq} \mathrm{kg}$ of ${ }^{137} \mathrm{Cs}$ was added to the medium containing $0.1 \%$ stable $\mathrm{Cs}$, both $0.1 \%$ stable $\mathrm{Cs}$ and $0.1 \% \mathrm{~K}$ or $0.5 \% \mathrm{~K} .{ }^{137} \mathrm{Cs}$ concentrations in the fruiting bodies separated from medium were determined with a $\mathrm{Ge}$ detector. The stable $\mathrm{Cs}$ concentrations were mesured by INAA, and $\mathrm{K}$ content was determined by flame photometry.

\subsection{Microorganisms in mushroom substrata and soils}

\subsection{Number of bacteria and actinomycetes from mushroom suhstrata and soils}

Each dried soil sample ( $1 \mathrm{~g})$ was suspended in $6 \%$ yeast extract broth, and aliquots of the suspensions were plated onto YM (yeast extract-malt extract) agar for bacteria and HV (humic acid and vitamin) agar for actinomycetes. After incubation at $27^{\circ} \mathrm{C}$ for $7 \mathrm{~d}$, the colonies on the $\mathrm{YM}$ and $\mathrm{HV}$ plates were counted.

\subsubsection{Cs uptake by actinomycetes isolated from a mushroom substratum}

Preincubated 3d cultures of the strains of actinomycetes in R2YE medium were used for inoculation. A certain quantity of culture was inoculated into $30 \mathrm{ml} \mathrm{YM}$ broth containing $\mathrm{CsCl}$ and then incubated at $27{ }^{\circ} \mathrm{C}$ for $4 \mathrm{~d}$ with shaking. Mycelia were harvested by centrifugation, washed twice with distilled water and freeze-dried. The dried mycelia were digested with $\mathrm{HNO}_{3}-\mathrm{H}_{2} \mathrm{O}_{2}$. The $\mathrm{Cs}$ and $\mathrm{K}$ contents of mycelia were determined by flame photometry.

\subsubsection{SEM observation and elemental analysis of cultured mycelia of actinomycetes}

The mycelia of $S$. lividans TK24 and Streptomyces sp. TOHO-2 cultured on YM agar containing $10 \mathrm{mM} \mathrm{Cs}$ for $7 \mathrm{~d}$ were observed by SEM (Hitachi Co., Ld. S-3500N). Elemental analysis was carried out as described by Kato et al. [12].

\subsection{4 ${ }^{133} \mathrm{Cs}-\mathrm{NMR}$ analysis for cultured mycelia of S. lividans TK24}

${ }^{13}$ Cs-NMR analysis of the mycelia of $S$. lividans TK24, cultured in YM broth containing $10 \mathrm{mM} \mathrm{Cs}$ in the medium, was performed by NMR spectrometry with an external reference capillary tube containing $100 \mathrm{mM}$ $\mathrm{CsCl}$ and $50 \mathrm{mM}$ Dy $\left(\mathrm{P}_{3} \mathrm{O}_{10}\right)^{7}$, as described by Kuwahara et al. [9].

\section{RESULTS AND DISCUSSION}

\subsection{Concentrations of ${ }^{137} \mathrm{Cs}$ and stable $\mathrm{Cs}$ in wild mus hrooms, mushroom substrata and soils}

Figures 1(a) and (b) show the concentrations of ${ }^{137} \mathrm{Cs}$ and $\mathrm{Cs}$ in wild mushrooms, mushroom substrata and soils together with the previous findings of Sugiyama et al. from Mt. Fuji, Japan, respectively [1, 10]. We confirmed that the ${ }^{137} \mathrm{Cs}$ concentrations in the wild mushrooms were $2-4$ orders of magnitude higher than those in other vegetables in Japan, although over 10 years have passed since the Chernobyl accident [13]. The ${ }^{137} \mathrm{Cs}$ concentrations in mushroom substrata and soils were several times higher than those of surface soils (0$5 \mathrm{~cm}$ ) collected from various areas in Japan in the same year [13]. The ${ }^{137} \mathrm{Cs}$ concentrations in both mushrooms and substrata were found to have a gradual decrease in comparison with the samples collected in $1989-1990$ and $1996[1,10]$. The wild mushrooms incorporated larger amounts of stable $\mathrm{Cs}$ as well as ${ }^{137} \mathrm{Cs}$ than agricultural plants such as potatoes, cabbages and rice collected in Japan $[14,15]$. The Cs levels in mushroom

(a) $137 \mathrm{Cs}$

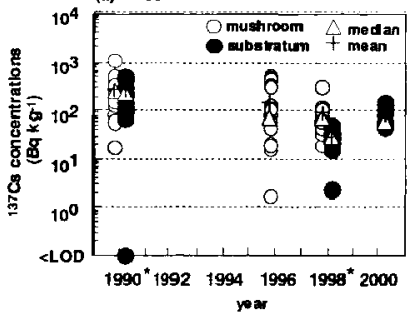

Figure 1: ${ }^{137} \mathrm{Cs}$ and $\mathrm{Cs}$ concentrations in mushrooms, substrata and soils The concentrations in mushrooms were based on fresh weight, and those in substratum were based on dry weight. * Data of Sugiyana et al. $[1,10]$ 
substrata and soils were similar to the other soils from Japan [15].

\subsection{Uptake of ${ }^{137} \mathrm{Cs}$, $\mathrm{Cs}$ and $\mathrm{K}$ by cultured fruiting bodies of the mushroom $P$. ostreafus}

The ${ }^{137} \mathrm{Cs}$ concentrations in the cultured fruiting bodies of $P$. astreatus $\mathrm{Y} \cdot 1$ in medium with $10 \mathrm{kBq}^{\mathrm{kg}} \mathrm{g}^{-1}$ were 2-3 orders of magnitude higher than those in wild mushrooms, as mentioned above. The values decreased dependent on the addition of $\mathrm{Cs}$ and/or $\mathrm{K}$ to the medium, as shown in Figure 2. The ${ }^{137} \mathrm{Cs}$ uptake by fruiting bodies was inhibited by $\mathrm{K}$ and/or $\mathrm{Cs}$. This suggests that the mushroom $P$. ostreatus $\mathrm{Y}-1$ might uptake ${ }^{137} \mathrm{Cs}$ via $\mathrm{K}$ transport systems.

Concentration ratios are used as parameters for discussing the characteristics of elements accumulated by plants and mushrooms. The substratum-to-mushroom concentration ratio (CR) is defined follows:

$\mathrm{CR}=\frac{\text { Concentration in mushroom }\left(\mathrm{Bq} \mathrm{kg}{ }^{-1} \mathrm{dry} \text { wt. for }{ }^{137} \mathrm{Cs} \text { or } \mathrm{mg} \mathrm{kg}^{-1} \mathrm{dry} \text { wt. for } \mathrm{Cs}\right)}{\text { Concentration in substratum }\left(\mathrm{Bq} \mathrm{kg}{ }^{-1} \text { fresh wt. for }{ }^{137} \mathrm{Cs} \text { or } \mathrm{mg} \mathrm{kg}^{-1} \text { fresh wt. for Cs) }\right.}$

Figure 3 shows the range, median and mean of the $\mathrm{CR}$ for ${ }^{137} \mathrm{Cs}$ and $\mathrm{Cs}$ in cultured mushrooms along with the wild mushrooms examined in this study. The CRs of ${ }^{137} \mathrm{Cs}$ and $\mathrm{Cs}$ nearly agreed for both wild and cultured mushroorns, and the CRs of cultured mushrooms were markedly higher than those of wild mushrooms. From these findings, it was demonstrated that ${ }^{137} \mathrm{Cs}$ and $\mathrm{Cs}$ are actively uptaken by mushrooms depending on the ${ }^{137} \mathrm{Cs}$ or $\mathrm{Cs}$ concentrations in the medium.

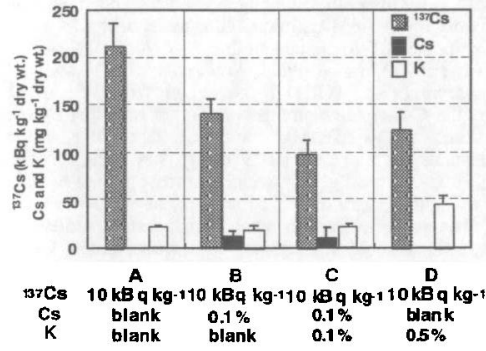

$13 \mathrm{Cs}, \mathrm{Cs}$ and $\mathrm{K}$ concentrations in medium

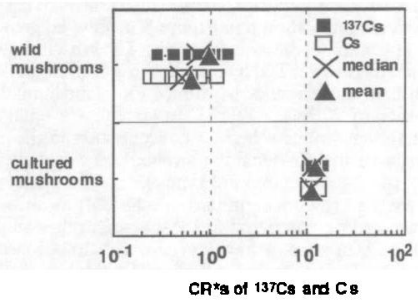

Feure 3: Ranges of CR $\mathrm{C}$ s of ${ }^{137} \mathrm{Cs}$ and Csand median and mean for wild and cultur ed mustr ooms. ${ }^{\star} \mathrm{CR}$ indicates concentration ratio.

Figure 2: Concentraions of ${ }^{137} \mathrm{Cs}, G$ and $K$ in cultured fr uiting bodies of mushroum ( $P$. ostreatus $Y-1$ ) inmedia at various ${ }^{137} \mathrm{Cs}, \mathrm{Cs}$ and/or $\mathrm{K}$ concentrations.

\subsection{Experiments on microorganisms in mushroom substrata and soils}
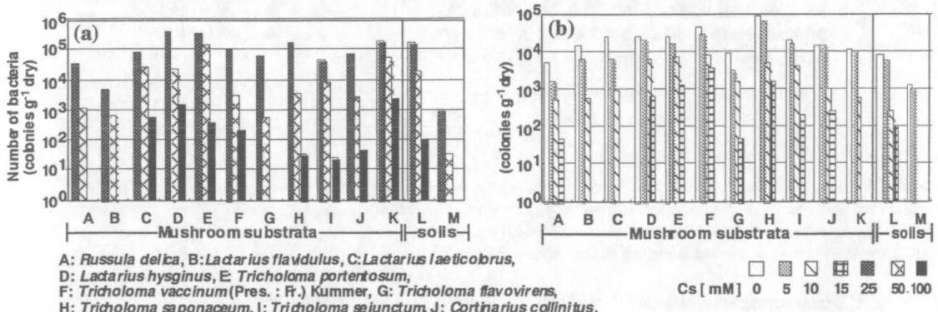

A: Russula delica, B: Lactarius fla vidulus, C:Lactari

F: Tricholoma vaccinum(Pres. : F.) Kummer, G: Tricholoma flavovirens,

H: Tricholoma saponaceum, I: Tricholoma $x_{j u n c t u m} \mathrm{~J}$ : Cortharius collinitus,

K: Boletopsis leucomelas, L: Mt. Fuji (1600m), M: Mt Fuji (2200m)

Figure 4: Number of microorganisms in mushroom substratum and soils. (a) bacteria grown on YM agar containing 25 to $100 \mathrm{mMCs}$ and(b) actinomyce tes grownon $\mathrm{HV}$ agar containing $0 \mathrm{~b} 25 \mathrm{mMCs}$. 


\subsubsection{Number of bacteria and actinomycetes in mushroom substrata and soils}

The number of bacteria and actinomycetes present in mushroom substrata and soils when $\mathrm{CsCl}$ was added to $\mathrm{YM}$ agar and HV agar are show' $n$ in Figure 4. Both of the number decreased with increasing Cs concentration in agar. Colonies of bacteria were observed from all substrata and soil samples up to $50 \mathrm{mM}$ $\mathrm{Cs}$ in YM agar. In 9 of 13 samples, bacterial colonies were observed even in the presence of $100 \mathrm{mM} \mathrm{Cs}$. In contrast, colonies of actinomycetes from all samples were seen only up to $5 \mathrm{mM} \mathrm{Cs}$ in HV agar. The colonies appeared in $92 \%$ of all samples at $10 \mathrm{mMCs}$, and in $62 \%$ at $15 \mathrm{mM} \mathrm{Cs}$. In the presence of $25 \mathrm{mM}$ $\mathrm{Cs}$, no actinomycetes could be detected any samples. These findings show that actinomycetes in mushroom substrata and soils are more sensitive to Cs than bacteria. There was no distinct difference in the patterns of appearance of bacteria and actinomyces from substrata and soil samples. Additionally, the Cs concentrations in substrata and soils examined in this study did not influence on the number of soil microorganisms.

\subsubsection{Cs uptake by actinomycetes isolated from mushroom substratum}

We investigated the $\mathrm{Cs}$ sensitivity of the strains of actinomycetes isolated from an edible mushroom substratum. Approximately $60 \%$ of the actinomycetes isolated from mushroom substratum could not grow in the presence of over $10 \mathrm{mM}$ Cs. Figures 5(a), (b) and (c) show the growth and Cs uptake of several strains of actinomycetes, which differ in Cs sensitivity, in YM broth containig $5 \mathrm{mM} \mathrm{Cs}$. The most Cssensitive strains shown in Figure 5(a) showed growth only up to $5 \mathrm{mM} \mathrm{Cs}$ in medium, while 5(b) was up to $10 \mathrm{mM} \mathrm{Cs}$ and 5(c) was $15 \mathrm{mM} \mathrm{Cs}$. The growth and Cs uptake of Cs-resistant strains, S. lividans TK24 and Streptomyces sp. TOHO-2, are shown in Figures 5 (d) and (c), respectively. S. lividans TK24 showed growth in the presence of $50 \mathrm{mM} \mathrm{Cs}$ in medium. Streptomyces $\mathrm{sp}$. TOHO-2 showed growth even in the presence of $200 \mathrm{mM} \mathrm{Cs} \mathrm{[12].} \mathrm{In} \mathrm{gencral,} \mathrm{Cs} \mathrm{uptake} \mathrm{by} \mathrm{the} \mathrm{Cs-sensitive} \mathrm{strains} \mathrm{was} \mathrm{higher} \mathrm{than} \mathrm{that} \mathrm{by} \mathrm{the}$ Cs-resistant strains when $\mathrm{Cs}$ concentration in the medium was low $(5 \mathrm{mM})$. The concentration of $\mathrm{K}$ in the mycelia of the Cs-sensitive strains was relatively constant (the range of $10-19 \mathrm{mg} \mathrm{g}$ dry weight). The range of $\mathrm{Cs}$ concentration in mushroom substrata was $0.62-2.2 \mathrm{mg} \mathrm{kg}^{-1}$ dry weight (corresponding to 0.2 $1.5 \mathrm{mg} \mathrm{kg}$ fresh weight and $1.5-11 \mu \mathrm{M}$ ) as shown in Figurc 1, and the Cs concentrations in nature were extremely low compared to those used in this study. The actinomycetes in mushroom substrata tended to uptake Cs present at low levels in substrata more than the Cs-resistant strains, and to accumulate Cs in mycelia. Therefore, we suppose that the highest ${ }^{137} \mathrm{Cs}$ concentrations were found in the surface layers in most cases, since microorganisms such as actinomycetes in the surface soils will uptake ${ }^{137} \mathrm{Cs}$ and store it in the cells or mycelia.
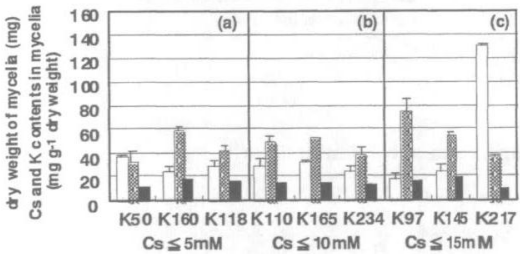

Strains is olated from mushroom substratum

$$
\begin{aligned}
& \text { 口: dry weight of mycelia } \\
& \text { ㅊ: Cs } \\
& \text { a : K }
\end{aligned}
$$

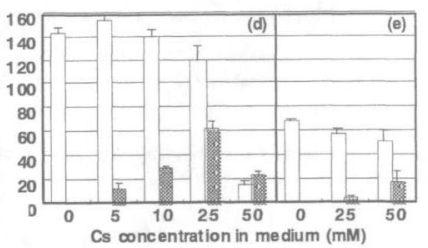

Streptomyces Iividans TK24 тонО-2

Figure 5: Concentrations of $C$ s and $K$ in capa ated into actinam yces, and growth Strains in (a, band c) were isolated from mus hroom substratum. (a), (b) and (c)could grow with up to 5, 10 and $15 \mathrm{mM}$ C's in mectia, respectivd y. The strains were culturedin the presence $5 \mathrm{mM} \mathrm{Cs}$ for $4 \mathrm{~d}$. S Ividous TK24 (d) and Srepomyca 9 . TO HO-2 (e) showed growthin up to $50 \mathrm{mM}$ and $200 \mathrm{mMCs}$ and we re cultured at $v$ a ious Cs concentrations.

\subsubsection{SEM observation and elemental analyses of aultured mycelia of actinomycetes}

The mycelia of $S$. lividans TK24 and Streptomyces sp. TOHO-2 grown on YM agar containing $10 \mathrm{mM}$ and $50 \mathrm{mM} \mathrm{Cs}$, respectively, were examined (Figure 6 ). We observed brilliant spots in the mycelia of both strains, but no such spots were observed in the mycelia grown on Cs-free medium (data not shown). 
Subsequently, we performed elemental analyses of the brilliant spots in the mycelia of $S$. lividans TK24 by SEM-EDX. In areas containing a brilliant spot, distinctive peaks for $P$ and Cs werc observed, whereas only weak peaks for $\mathrm{P}$ and $\mathrm{Cs}$ in other areas were seen [12]. These observations indicate that the $\mathrm{Cs}$ incorporated into the mycelia of $S$. lividons TK24 was condensed and accumulated in particular regions where the $P$ concentration was high. This finding may be related to the intracellular detoxification of Cs by organisms.

(a)

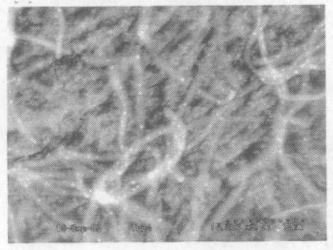

Figure 6: Scanning electron micrographs for S. lividans (a) and Streptomyces sp. TOHO-2

(b). The mycelia were inoculated onto membrane filters on YM agar containing $10 \mathrm{mM}$ (a) or $50 \mathrm{mM} \mathrm{CsCl}$ (b) for $10 \mathrm{~d}$. The mycelia on the membrane filter were subjected to SEM. Bar indicates $10 \mu \mathrm{m}$. (b)

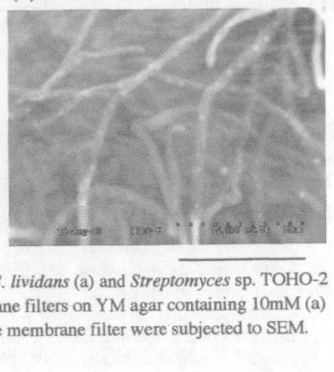

\subsection{4 ${ }^{133} \mathrm{Cs}-N M R$ analysis for cultured mycelia of S. lividans TK24}

We perfomed ${ }^{133} \mathrm{Cs}-\mathrm{NMR}$ analyses to estimate the state of $\mathrm{Cs}$ in the mycelia of $S$. lividans TK24 cultured in YM broth containing $10 \mathrm{mM}$ Cs. Figure 7 shows two representative ${ }^{133} \mathrm{Cs}$ spectra from cultured mycelia in the presence of $10 \mathrm{mM} \mathrm{Cs}$ (a) and the medium after harvesting the mycelia (b). In the spectra from the mycelia of $S$. lividars TK24, two relatively broad signals at approximately 2 and $5 \mathrm{ppm}$ in the lower field were observed, with the external reference of $100 \mathrm{mM} \mathrm{CsCl}$ and $50 \mathrm{mM}$ Dy $\left(\mathrm{P}_{3} \mathrm{O}_{10}\right)^{7}$ at $14.5 \mathrm{ppm}$. In the medium after harvesting, one signal at $0 \mathrm{ppm}$ corresponding to free $\mathrm{Cs}^{+}$was seen. We supposed that these lower ficld signals in the spectra of mycelia were derived from the $\mathrm{Cs}^{+}$trapped subcellulary, as in the cytoplasm and vacuoles, as reported by Pfeffer P. E. et al. [16].

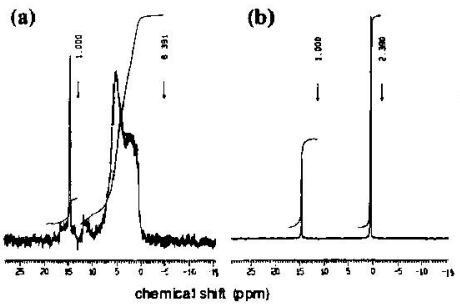

Figure 7: ${ }^{133} \mathrm{Cs}-\mathrm{NMR}$ spectra (at $52.3 \mathrm{MHz}$ ) of the cultured myclia of 5 . lividans TK24 (a) and medium containing $10 \mathrm{mM} \mathrm{Cs} \mathrm{(b).} \mathrm{The} \mathrm{mycelia} \mathrm{of} S$. lividans TK24 cultured in YM broth with $10 \mathrm{mM} \mathrm{CsCl}$ for $4 \mathrm{~d}(\mathrm{a})$ and medium after harvesting the mycelia (b). The signals at $14.5 \mathrm{ppm}$ in both spectra (a) and (b) are derived from $100 \mathrm{mM}{ }^{133} \mathrm{Cs}$ in the external reference.

\section{CONCLUSION}

In this study, the concentrations of ${ }^{137} \mathrm{Cs}$ and $\mathrm{Cs}$ in wild mushrooms and in the substrata, the habitat of the fruiting body mycelia, were determined. We investigated the Cs sensitivity of microorganisms in the substrata, and found that actinomycetes were more sensitive to Cs than other bacteria, and that they accumulated $\mathrm{C} s$ in mycelia. In addition, there are some reports that other bacteria, such as $R$ hodococcus $\mathrm{sp}$. strains CS98 and CS402, Escherichia coli and Bacillus subtilis incorporated Cs into the cells $[17,18]$. ${ }_{137} \mathrm{Cs}$ in mushroom substrata might be concentrated there because these microorganisms inhabit the substrata and accumulate Cs.

The findings of SEM-EDX and ${ }^{133} \mathrm{Cs}-\mathrm{NMR}$ analyses suggest that $\mathrm{Cs}$ taken up by the mycelia of $S$. ividans TK24 might be concentrated in limited regions, such as vacusoles, for detoxification of intracellular $\mathrm{Cs}$. 


\section{Acknowledgments}

This research was partially supported by the Ministry of Education, Science, Sports and Culture, Grant-in Aid for scientific research (C), 12680554, 2000. We are grateful to Dr. H. Shibata (Yamanashi Forestry and Forest Products Research Institute) for sampling and identification of mushrooms, Dr. K. Matsushita and Dr. M. Nishina (Saitama medical school) for ${ }^{133} \mathrm{Cs}-\mathrm{NMR}$ measurements, Dr. Y. Morita (Horiba Co., Ltd.) for SEM-EDX analysis and Ms. Ikuyo Iijima and Mr. Hiroyuki Takagi (Kanagawa Prefectural Public Health Laboratory) for INAA. We would also like to Miss A Oosone (Toho University) for technical assistance.

\section{References}

[1] Sugiyama H., Shibata H., Isomura K. and Iwashima K., J. Food Hyg. Soc. Japan 35 (1994) 13-22.

[2] Yoshida S. and Muramatsu Y., Sci. Total Environ. 157 (1994) 197-205.

3] Tsukada H., Shibata H. and Sugiyama H., J. Environ. Radioactivity 39 (1998) 149-160.

[4] Brückmann A. and Wolters V., Sci. Total Environ. 157 (1994) 249-256.

[5] Guitlitte O., Melin J. and Wallberg L., Sci. Total Environ. 157 (1994) 207-215.

[6] Olsen R. A., Joner E. and Bakken L. R., in Proceedings of CEC Workshop, Transfer of Radionuclides in Natural and Semi-Natural Environments, edited by G. Desmet, P. Nassimbeni and M.Belli. (Elsevier, London, 1990), pp. 657-663.

[7] Saikawa M. and Wada N., Trans. Mycol. Soc. 27 (1986) 113-118.

[8] Thorn R. G. and Barron G. L., Science 224 (1984) 76-78.

[9] Kuwahara C., Watanuki T., Matsushita K., Nishina M. and Sugiyama H., J. Radioanal. Nucl. Chem. $235(1-2)(1998)$ 191-194.

[10] Sugiyama H., Terada H., Shibata H., Morita Y. and Kato F., J. Health Sci. 46 (2000) 370-375.

[11] Sugiyama H., Terada H., Isomura K. and Tsukada H. and Shibata H., Radioisotopes 42 (1993) 683-690 (in Japanese with English abstract).

[12] Kato F., Kuwahara C., Oosone A, Ichikawa T., Terada H., Morita Y. and Sugiyama H., J. Health Sci. 46 (2000) 259-262.

[13] NIRS, Radioactivity survey data in Japan (National Institute of Radiological Science, Chiba, 2000) Nos.126, 127, 128 and 129 .

[14] Tsukada H., Nakamura Y., J. Radioanal. Nucl, Chem. 236 (1-2) (1998) 123-131.

15] Tsukada H., Nakamura Y., Sci. Total Environ. 228 (1999) 111-120.

[16] Pfeffer P. E., Rolin D. B., Brauer D., Tu S. and Kumosinski T. F., Biochimica et Biophysica Acta 1054 (1990) 169-175.

[17] Tomioka N., Uchiyama H. and Yagi O., Appl. Ebviron. Microbiol. 58 (1992) 1010-1023.

[18] Perkin J. and Gadd G. M., J. Indust. Microbiol. 14 (1995) 218-225. 